\section{Development of a Structural Optimization Strategy for the Design of Next Generation Large Thermoplastic Wind Turbine Blades}

\author{
Louis-Charles Forcier . \\ Simon Joncas
}

Received: date / Accepted: date

\begin{abstract}
This paper presents the development of a structural optimization process for the design of future large thermoplastic wind turbine blades. The optimization process proposed in this paper consists of three optimization steps. The first step is a topology optimization of a short untwisted and non tapered section of the blade, with the inner volume used as the design domain. The second step is again a topology optimization, but on the first half of a blade to study the effect of non symmetry of the structure due to blade twist and taper. Results of this optimization step are then interpreted to build a shell model of the complete blade structure to perform composite size optimization based on a minimum mass objective subjected to constraints on deflection, composite strength and structural stability. Different blade models using ribs are then optimized and compared against conventional blade structure (spar box structure without ribs and single web structure without ribs). The use of ribs in wind turbine blade structures, which is more adapted to thermo-
\end{abstract}

This paper incorporates elements of papers presented at the 51st AIAA/ASME/ASCE/AHS/ASC Structures, Structural Dynamics, and Materials Conference (12-15 April 2010, Orlando, Florida, United States) and at the 10th AIAA/ISSMO Multidisciplinary Analysis and Optimization Conference (30 August - 1st Septembre 2004, Albany, New York, United States).

Louis-Charles Forcier

Ph.D. student

Department of Mechanical Engineering

E-mail: louis-charles.forcier.1@ens.etsmtl.ca

Simon Joncas

Associate professor

Department of Automated Manufacturing Engineering

E-mail: simon.joncas@etsmtl.ca

École de technologie supérieure

1100, Notre-Dame West, Montréal, Québec, Canada, H3C 1K3 plastic composite manufacturing than for thermoset composites, leads to slightly lighter blades than conventional blade structures.

Keywords Wind energy · Thermoplastic composite · Wind turbine blades $\cdot$ Structural optimization

\section{Introduction}

The last 30 years of thermosetting composite wind turbine blade development yielded three distinct structural concepts: the monolithic skin monocoque concept (based on Ulrich Hutter's pioneering design in 1959), the single shear web design, and the double shear web or box spar concept (see figure 1). The last three decades also saw non-negligible improvements in manufacturing techniques while most manufacturers moved away from the classic hand lay-up process towards vacuum infusion methods or pre-pregging (Veers et al, 2003). From a material point of view, measures were also taken to improve blade performance. New glass fabrics were introduced and meticulous use of carbon fibers for highly stressed areas is now common in large blades. Resin systems also evolved from basic polyester-based systems to vinylester and epoxy systems (Griffin, 2002). Finally, numerous improvements were also made to blade root details with manufacturers refining their design from first generation heavy one-piece metallic flanges to lighter flange designs and bonded-in sleeves and stud connections. As a result of these improvements, thermosetting composite blade weight with respect to length was remarkably well controlled by designers and manufacturers. Theoretically, if materials and structural concept are kept unchanged during an upscaling process, mass should evolve as a cubic function of blade length. On the contrary, due to the above mentioned improvement to the design, manufacturing processes and materials, blade mass scaled closer to a square law over the years (Veers et al, 2003).

The wind energy industry has witnessed an impressive growth rate over the last two decades. Consequently, the wind energy composite market has experienced a steady growth rate of $20 \%$ over the past couple of years and should surpass the aerospace market with 618,000 tons consumed per year compared to 515,000 tons by 2013 (JEC Composites, 2009). As a consequence of blade life being limited to 20 years, blade scrap tonnage should be in the same order of magnitude by 2030 and rise by $20 \%$ each year. Judging from these numbers, it is obvious that the industry will have to take their responsibilities regarding blade recycling. Unfortunately, since thermosetting resin are not well suited for primary recycling, it is possible that the industry will be forced to switch to more sustainable resin systems as it was the case for the European automotive composite industry when the vehicle end-of-life legislation came into effect. 
In this context, this paper proposes a design solution for future large, fully recyclable, thermoplastic composite blades. As it will be explained in section 2, the design solution proposed in this paper was not based on existing blade designs but rather developed using a three steps structural optimization techniques. The geometry of the studied blade and the design load cases will be presented in sections 3 and 4 respectively. The optimization process will be presented in section 5 and the models and results of each optimization step will be presented in sections 6, 7 and 8. The different designs will then be compared and a final design will be proposed.

\section{Thermosetting composite blade design vs TPC design}

The structural design used today for large thermosetting (mainly epoxy and vinylester) composite wind turbine blades relies on a box spar as the main load-bearing element. Two general philosophies may be applied to yield such a design. As shown in figure $2 \mathrm{a}$, the box spar can be formed from two $\mathrm{C}$-shaped webs bonded to upper surface and lower surface blade skins bonded at the leading edge and trailing edge. In this case, the blade skins are heavily reinforced in the area comprised between the two webs (often called the spar caps) to close the box spar and provide an adequate load path. Instead of using two C-shaped webs, some manufacturers prefer producing the box spar individually on a dedicated mandrel (approach preferred by Vestas, Gamesa and others). This seamless box spar is later joined to non-structural upper and lower surface skins to give the blade its final shape. This design philosophy is illustrated in figure $2 \mathrm{~b}$. With both designs, leading edge and trailing edge sections of the blade use sandwich panels but no ribs to withstand the aerodynamic load they are subjected to.

TPC manufacturing processes in use today are mostly fast melt processes dedicated to the production of relatively small low cost parts (up to 1-2 $\mathrm{m}$ in length and 1-5 mm thick). Although reactive processing techniques for TPC based on vacuum infusion are currently being developed to produce thick large parts (van Rijswijk, 2007), it is still technically impossible for manufacturers to simply replace their existing thermosetting resin systems by thermoplastic resins systems while keeping the same manufacturing process and blade structural design. Consequently, although TPC are certainly appealing on a recycling point of view, blade manufacturers have not made the switch to thermoplastic resin systems. Only a few demonstrator projects for TPC wind turbine blades were reported since the mid-nineties. In 1996, a demonstrator blade was built at the Ris $\varnothing$ National Laboratory (Denmark) using Comfil glass/PET commingled fabrics (Lystrup et al, 1998). Using vacuum to consolidate the laminate, isothermal melt processing of a $3.2 \mathrm{~m}$ long airfoil section was performed at $225^{\circ} \mathrm{C}$. A couple of years later,
Bonus (now Siemens) used the expertise of Ris $\emptyset$ to develop a glass/PP composite blade (Lystrup, 2006). The concept was validated with the fabrication of a $0.5 \mathrm{~m}$ long blade section melt processed under vacuum at $180^{\circ} \mathrm{C}$. Recently, interest in TPC for wind turbine blades was revived through the concerted effort of ÉireComposites, Cyclics Corporation and Mitsubishi. ÉireComposites, who already produces small glass/PP (Twintex) blades for $6 \mathrm{~kW}$ and $15 \mathrm{~kW}$ machines, produced a $12.5 \mathrm{~m}$ demonstrator blade using glass/PBT (Cyclics).

Since material processing is very different for TPC than for thermoset based composites, to be able to maximize the potential of thermoplastic composites when used for large wind turbine blade structures, the design proposed later in this article was not based on existing blade designs but rather developed using structural topology optimization techniques.

\section{Blade geometry}

Targeting next generation wind turbines, the blade studied in this paper is meant for a $150 \mathrm{~m}, 3$-bladed, up-wind, variable speed and pitch regulated wind turbine. The nominal power $(P)$ of the turbine is $8 \mathrm{MW}$ at a rated wind speed $\left(V_{r}\right)$ of $12 \mathrm{~m} / \mathrm{s}$. The blade tip speed ratio $(\lambda)$ is 7.5 up to rated wind speed. Between this wind speed and the cut-out wind speed ( $V_{\text {out }}$ ) of $25 \mathrm{~m} / \mathrm{s}$, the rotational speed is fixed at $\Omega=11.5 \mathrm{rpm}$. For this study, the hub height $(h)$ is set at $150 \mathrm{~m}$.

The blade's aerodynamic shape chosen for this study was adapted from van Rijswijk et al (2005) and Joncas et al (2005) and is based on current large wind turbine blade geometric trends. The maximum chord length $\left(c_{\max }\right)$ is set to $7.5 \%$ of blade length and is situated at $20 \%$ of the rotor radius $(R)$. The chord at tip is $20 \%$ of the maximum chord length and the distribution of chord is linear from the maximum chord position to blade tip. The hub radius is $5 \%$ of the rotor radius and the blade root diameter is set as $70 \%$ of $c_{\max }$. The distribution of twist is non-linear and is set to yield the design angle of attack in each blade elements for wind speed below rated wind speed.

Airfoils used for the aerodynamic part of the blade (from maximum chord position to tip) are DU series developed at Delft University of Technology for wind turbines (Timmer and van Rooij, 2003). Four different airfoils are used to allow a higher thickness to chord ratio in the highly loaded region near the root and a lower thickness to chord ratio near the tip. The region between the root and the maximum chord position evolves from a circular section to an airfoil shape. Table 1 shows the blade geometry where $r$ is the radial position of the chord station relative to the rotor's axis of rotation, $c$ is the chord length and $\theta_{T}$ is the twist angle. The blade pitch angle $\theta_{p, 0}$ (defined as the angle between the rotor plane and the blade tip chord line) is $-2^{\circ}$ for wind speeds 


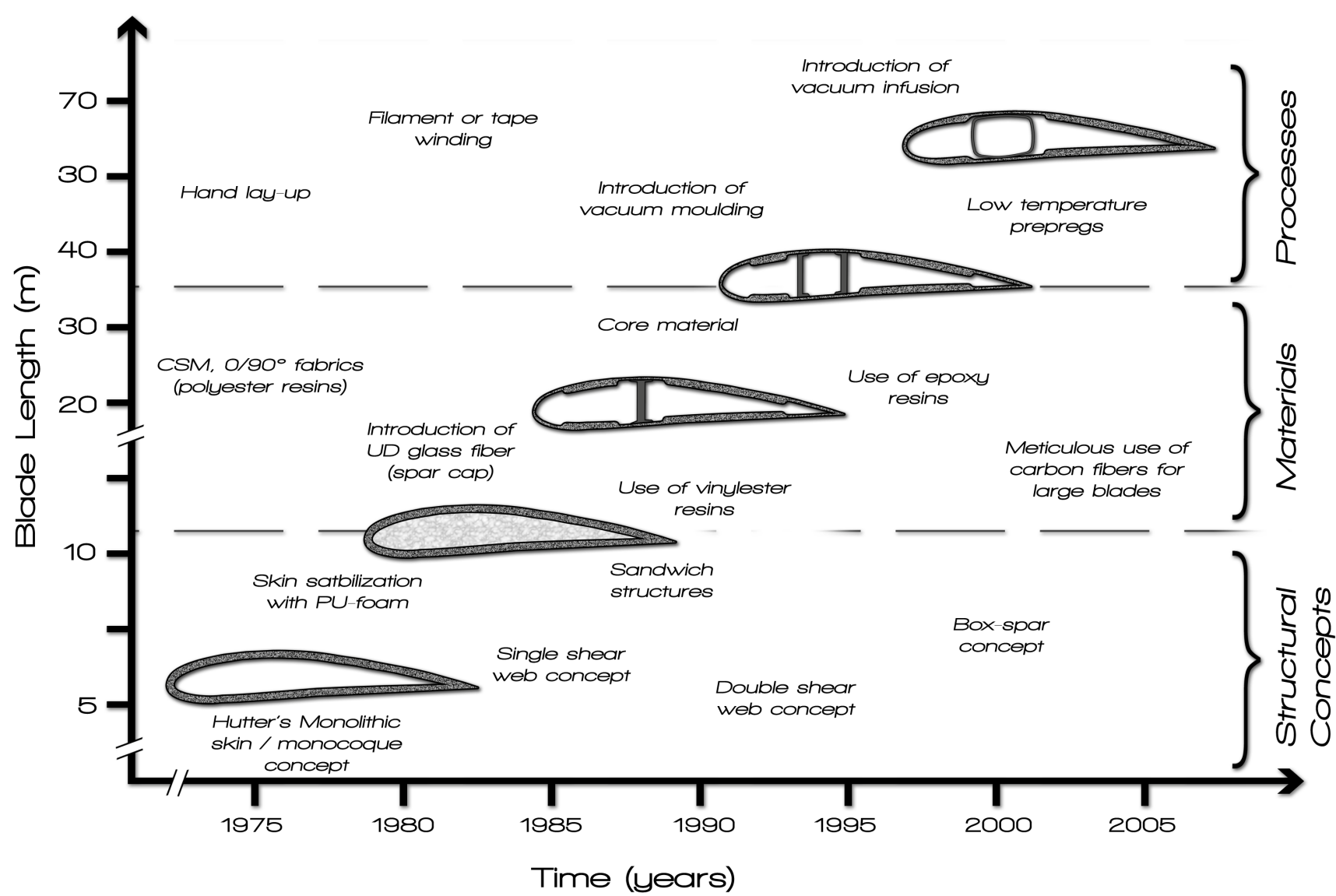

Fig. 1 Structural design concepts, materials and processes evolution of thermosetting fiber-reinforced composite wind turbine blades (1975-now).

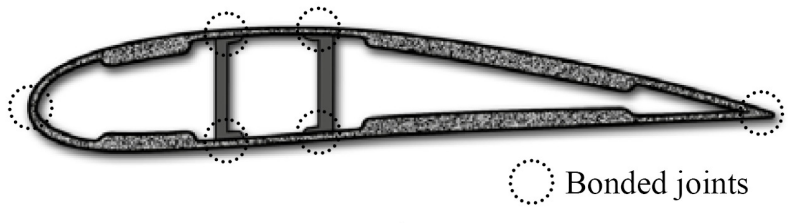

(a)

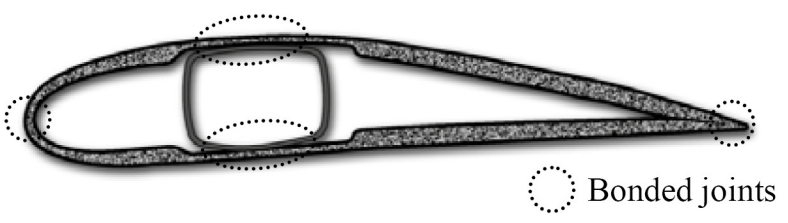

(b)

Fig. 2 Modern composite wind turbine blade structural designs. (a) Four-part C-shaped web and skin design. (b) Three part box-spar and nonstructural skin design.

under $12 \mathrm{~m} / \mathrm{s}$ (rated wind speed) and is adjusted to regulate power to $8 \mathrm{MW}$ for wind speeds above $V_{r}$.

\section{Design Loads}

Loads on the wind turbine blade have been determined according to the IA wind class of the International Electrotechnical Commission 61400-1 standard (International Electrotechnical Commission, 1999). This standard defines 8 different design situations for which the integrity of the turbine has to be validated: power production; power production plus occurrence of fault; start up; normal shut down; emergency shut down; parked (stand still or idling); parked and fault condition; transport, assembly, maintenance and repair. Ob-
Table 1 Blade geometry with corresponding airfoils.

\begin{tabular}{rrrc}
\hline \hline$r[\mathrm{~m}]$ & $c[\mathrm{~m}]$ & $\theta_{T}\left[^{\circ}\right]$ & Airfoil \\
\hline 3.750 & 3.938 & - & Circle \\
15.000 & 5.625 & 21.2 & DU-97-W-300 \\
21.667 & 5.125 & 13.1 & DU-97-W-300 \\
28.333 & 4.625 & 8.2 & DU-97-W-300 \\
35.000 & 4.125 & 4.3 & DU-91-W2-250 \\
41.667 & 3.625 & 3.3 & DU-00-W-212 \\
48.333 & 3.125 & 2.1 & DU-00-W-212 \\
55.000 & 2.625 & 1.3 & DU-96-W-180 \\
61.667 & 2.125 & 0.7 & DU-96-W-180 \\
68.333 & 1.625 & 0.1 & DU-96-W-180 \\
75.000 & 1.125 & 0.0 & DU-96-W-180 \\
\hline \hline
\end{tabular}

viously, since this paper deals with preliminary blade de- 
sign, a large number of these design situations are impossible to evaluate since they require full wind turbine characteristics to be known (control systems, tower/foundation design, etc.). Therefore, this study only considered specific power production situations and parked design situations where only blade characteristics were sufficient to evaluate the design situation. The following two sections will present these design situations and corresponding load cases.

\subsection{Power production design situation}

For the power production design situation, the IEC 614001 standard defines 9 load cases ranging from normal wind profile driven load cases to extreme wind shear driven load cases. Again, a large number of these load cases require wind turbine design characteristics not available when at the stage of preliminary blade design (yaw alignment system speed, pitch control system speed, ... ). Therefore, out of the 9 load cases described, only the load cases using the following three wind conditions were evaluated :

- Normal wind profile model (NWM)

- Extreme wind shear:

- horizontal negative extreme wind shear (EWS (HN))

- horizontal positive extreme wind shear (EWS (HP))

- vertical extreme wind shear (EWS(V))

- 50 years recurrence extreme direction change:

- negative extreme direction change $\left(\mathrm{EDC}_{50}(\mathrm{~N})\right)$

- positive extreme direction change $\left(\mathrm{EDC}_{50}(\mathrm{P})\right)$

All load cases mentioned above have been evaluated at rated and cut-out wind speeds using AeroDyn (Laino and Hansen, 2002) and YawDyn (Laino and Hansen, 2003). YawDyn analyses the dynamic behavior of the blades of a horizontal axis wind turbine and calls the AeroDyn software to compute the aerodynamic loads on the blades using the blade element momentum theory. YawDyn allows different ways to model the rotor. For this project, we chose to model the out-of-plane bending of the blades by the hinge-spring model (hinge hub model in YawDyn) to simulate out-ofplane bending stiffness. The stiffness of the torsional spring was evaluated using the natural frequency of the blade evaluated with tools developed by van Rijswijk et al (2005). To compare the different load cases, we used the maximum bending moment at blade root $\left(M_{\max }\right)$ given by YawDyn (see table 2 ). The azimuth angle ( $\Psi$, which is 0 when the blade is pointing downward) of the blade when the maximum bending moment is reached is also presented in table 2 . It is worth nothing that these bending moments take into account aerodynamics, gravitational, inertial and dynamic loads.

As seen in table 2, the critical load cases are found to be those submitted to an extreme wind shear (EWS). The maximum in-plane load is found with a horizontal negative
Table 2 Out-of-plane and in-plane bending moments computed using YawDyn for the different power production load cases studied.

\begin{tabular}{lrrrr}
\hline \hline \multicolumn{1}{c}{ Load cases } & \multicolumn{2}{c}{ out-of-plane } & \multicolumn{2}{c}{ in-plane } \\
& $\begin{array}{c}M_{\max } \\
{[\mathrm{MNm}]}\end{array}$ & $\begin{array}{c}\Psi \\
{\left[{ }^{\circ}\right]}\end{array}$ & $\begin{array}{c}M_{\max } \\
{[\mathrm{MNm}]}\end{array}$ & $\Psi$ \\
& 15.205 & 186 & 7.249 & 266 \\
\hline NWP (0), rated & 4.417 & 188 & 6.851 & 260 \\
NWP (0), cut-out & 21.164 & 224 & 8.290 & 244 \\
EWS (V), rated & 19.231 & 233 & 9.145 & 270 \\
EWS (HN), rated & 19.602 & 142 & 7.249 & 266 \\
EWS (HP), rated & 13.973 & 190 & 9.916 & 221 \\
EWS (V), cut-out & 11.937 & 260 & 11.534 & 264 \\
EWS (HN), cut-out & 12.218 & 110 & 6.851 & 261 \\
EWS (HP), cut-out & 15.288 & 205 & 7.315 & 267 \\
EDC $_{50}(\mathrm{~N})$, rated & 15.205 & 186 & 7.249 & 266 \\
EDC $_{50}(\mathrm{P})$, rated & 4.417 & 188 & 6.851 & 260 \\
EDC $_{50}(\mathrm{~N})$, cut-out & 5.574 & 191 & 6.918 & 257 \\
EDC $_{50}(\mathrm{P})$, cut-out & \multicolumn{4}{c}{} \\
\hline \hline
\end{tabular}

extreme wind shear, when the blade is at the horizontal position on the side where the aerodynamic forces are in the same direction as the gravity loads and when the wind shear generates the highest wind speed. The vertical extreme wind shear produces the maximum out-of-plane bending moment when the blade is about $45^{\circ}$ away from being in the upward position. One of the reasons why the maximum load does not happen when the blade is pointing upward (and submitted to the highest wind speed due to wind shear) is that in that position, the wind speed in some blade sections is high enough to cause aerodynamic stall so the loads are reduced. Also, dynamic effects can cause a delay between the maximum wind field perceived by the blade and the maximum bending moment occuring at blade root.

\subsection{Parked design situation}

The parked situation loads have been computed with a MATLAB program. Two situations were simulated: one with the blade in the vertical position (pointing upward) and the other in the horizontal position (to add the gravity loads to the aerodynamics load). Both situations were computed with the 50 years extreme wind speed model (EWM). For the vertical blade case, wind coming from all directions was considered since the nacelle and blades are locked in place when the turbine is parked. For the horizontal blade case, any pitch angle between $-2^{\circ}$ (pitch angle for wind speed under rated speed) and $90^{\circ}$ (angle corresponding to the fully feathered position) were considered. The fact that a wind turbine fault can occur so that the blade is not in the fully feathering position when the extreme wind condition occurs is then taken into account.

As for the power production situation load cases, the bending moments (including gravitational loads) at root have been used to compare the loads. Here, to be able to compare loads with the power production situation, a flapwise/edgewise 
system was used in which the flapwise and edgewise directions correspond respectively to the out-of-plane and inplane directions when the blade is in the nominal pitch position $\left(0.9^{\circ}\right.$ as in section 4.1 for rated wind speed load cases). The maximum flapwise load $(28,889,351 \mathrm{Nm})$ was found when the blade is at the vertical position and the pitch angle is $-2^{\circ}$ (blade is perpendicular to the wind direction). The maximum edgewise load $(8,092,833 \mathrm{Nm})$ occurs when the blade is in the horizontal position and the pitch angle is $57^{\circ}$.

\subsection{Load cases for the optimization problem}

For the optimization problem, the four most critical load cases presented in the two last sections were considered :

- Load case 1: Vertical EWS with blade pointing in the upward direction, nominal wind speed (maximum power production out-of-plane root bending moment);

- Load case 2: Horizontal EWS with blade positioning horizontally, cut-out wind speed (maximum power production in-plane root bending moment);

- Load case 3: EWM with the blade pointing upward and perpendicular to the wind (maximum parked flapwise root bending moment);

- Load case 4: EWM with the horizontal blade at a pitch angle of $57^{\circ}$ (maximum parked edgewise root bending moment);

Note that for simplicity of modeling, we considered that the maximum load for load case 1 happens when the blade is pointing upward and not at an azimuth angle of $224^{\circ}$ as specified in table 2.

Although root bending moments could be considered similar for some load cases, it is important to note that these load cases are very different from each other. In power production load cases, most of the aerodynamic load comes from the outer part of the blade while most of the load come from the inner part of the blade in the parked design situations. Also, load cases with blade pointing upward produce loads that are larger in the flapwise direction than in the edgewise direction while cases with blades positioned horizontally produce loads that are in the same order of magnitude (when including gravity loads) in both directions. Because they are very different in nature, all of these load cases were kept for the optimization process to be sure that the optimized design will be able to support the different loads it is subject to.

Aerodynamic loads along the blade length for the four selected load cases (including load cases evaluated with YawDyn) used for the finite element models have been computed using blade element momentum (BEM) theory (Hansen, 2008) coded in MATLAB. This code does not take into account the dynamic effects of out-of-plane bending so loads of load case 1 have been increased by $10 \%$ in the finite element models because further studies in YawDyn shows that for this particular load case, dynamic effects increase the loads by $10 \%$.

These aerodynamic loads and associated shear force and bending moment diagrams for each load case are shown in figure 3 to 6 . According to the IEC 61400-1 standard, loads presented in this section have been increased by a safety factor when transfered to the finite element model. These safety factors are: 1.35 for the aerodynamic and gravity loads and 1.25 for the inertial loads.

\section{Design methodology}

The blade structural design optimization strategy proposed in this paper involves three steps: two initial topology optimization steps and a final sizing optimization step (see table 3). Step 1 deals with topology optimization of a short, non-twisted and non-tapered airfoil-shaped blade section. Presented in an earlier paper (Joncas et al, 2004), results of optimization runs performed with individual loads applied separately helped identify preferred load paths with respect to the type of load applied. When extending the study to combined load cases, a more general structural topology capable of withstanding multiple loads was identified and will be presented in section 6. Based on these results, a larger, half-blade model (root to blade mid-span) will be used to explore structural topologies in the transition area between the first airfoil-shaped blade section and the circular root blade section. This is done in step 2 of the optimization strategy (section 7). As mentioned in table 3 , buckling and material stress limits are not used as constraints in steps 1 and 2. This was not a big concern since it has been shown in numerous other design studies that simply maximizing stiffness while constraining the design volume fraction yields efficient designs for most classical load cases (Chen and Young, 2004; Krog et al, 2004; Amorosi, 2004). While bending is the main solicitation in our case, it is believed that topology optimization can be used with confidence for preliminary design purposes.

Finally, using the results of steps 1 and 2, a third study is performed to set specific blade dimensions. This last step, based on a generic shell element blade model, will use sizing optimization tools to determine shell thicknesses, laminate lay-ups and ply orientations for a blade designed for minimum weight subjected to tip deflection, stress and buckling constraints. The results of this sizing optimization procedure will be presented in section 8 . 


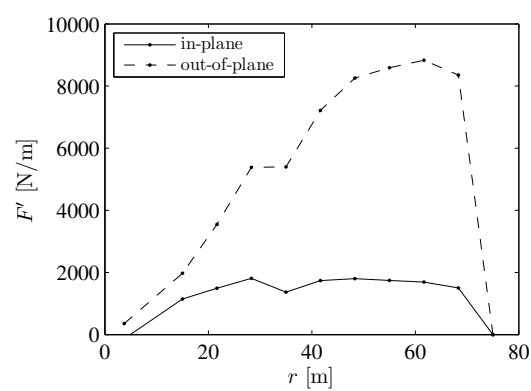

(a)

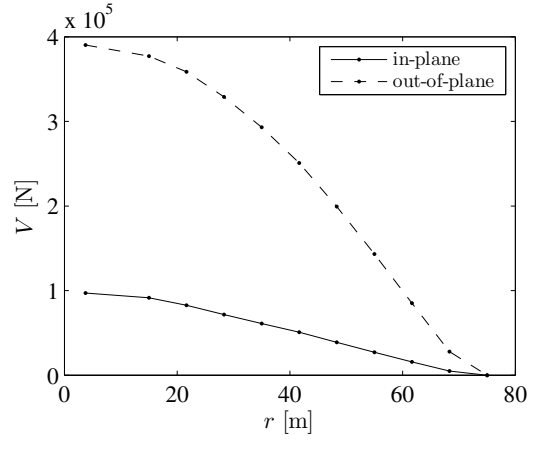

(b)

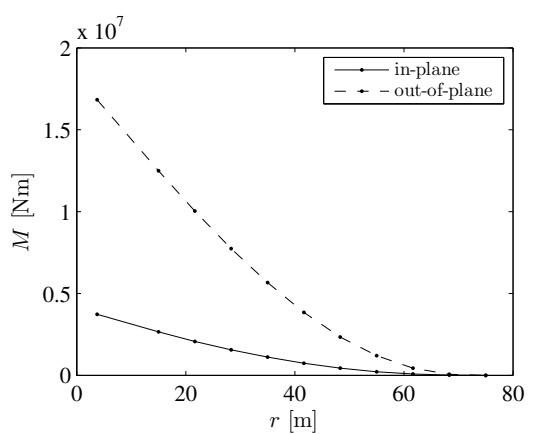

(c)

Fig. 3 Aerodynamic loads for load case 1 (vertical EWS with blade pointing in the upward direction, nominal wind speed). (a) Applied load ( $F^{\prime}$ ). (b) Shear force $(V)$. (c) Bending moment $(M)$.

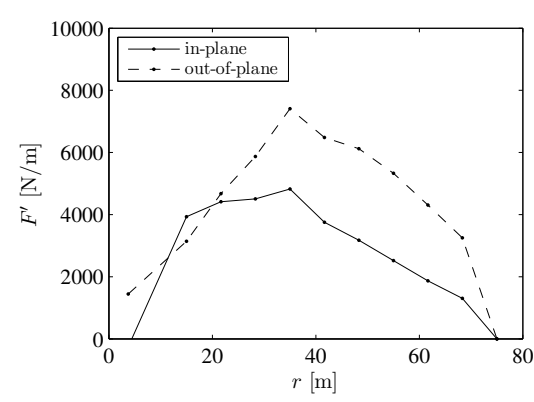

(a)

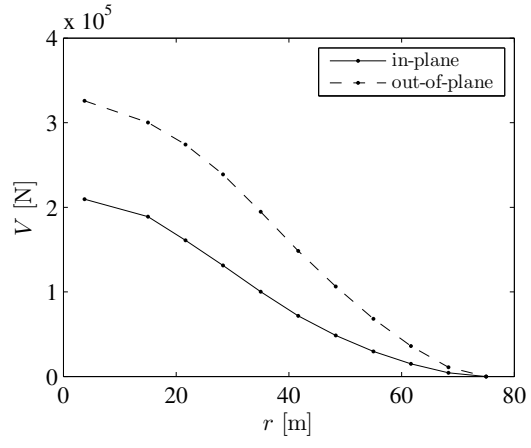

(b)

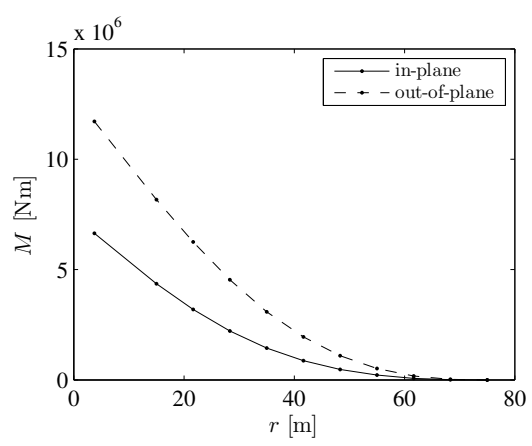

(c)

Fig. 4 Aerodynamic loads for load case 2 (horizontal EWS with blade positioning horizontally, cut-out wind speed). (a) Applied load ( $\left.F^{\prime}\right)$. (b) Shear force $(V)$. (c) Bending moment $(M)$.

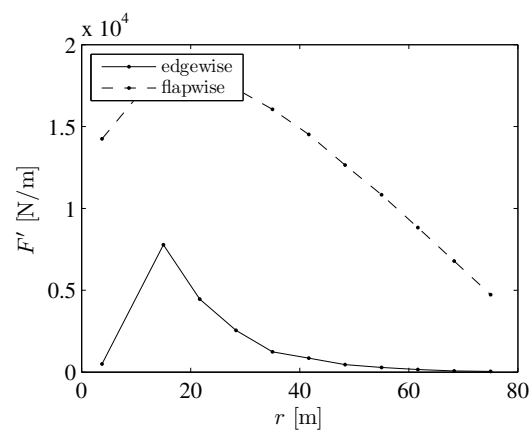

(a)

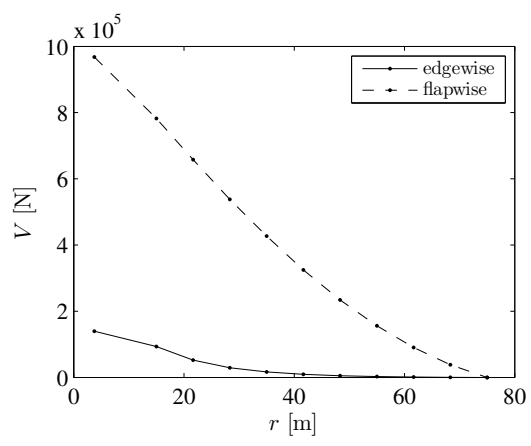

(b)

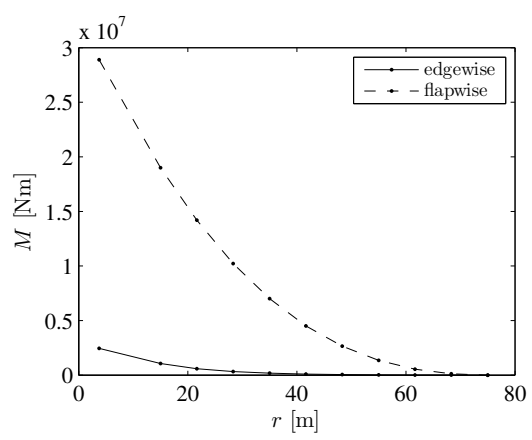

(c)

Fig. 5 Aerodynamic loads for load case 3 (EWM with the blade pointing upward and perpendicular to the wind). (a) Applied load ( $\left.F^{\prime}\right)$. (b) Shear force $(V)$. (c) Bending moment $(M)$.

Table 3 Optimization process.

\begin{tabular}{llll}
\hline \hline & Step 1 & Step 2 & Step 3 \\
\hline Part studied & Short section & Half-blade & Complete blade \\
Optimization type & Topology & Topology & Size \\
Design variables & Solid elements density & Solid elements density & Thickness of composite layers \\
Constraints & Fixed material volume fraction & Fixed material volume fraction & Failure index, tip deflection and buckling \\
Objective & Minimize compliance & Minimize compliance & Minimize mass \\
\hline \hline
\end{tabular}




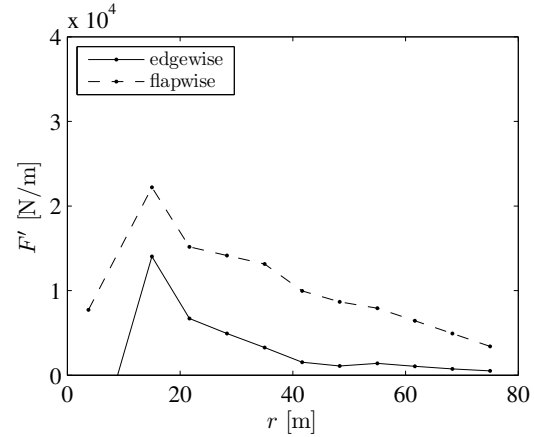

(a)

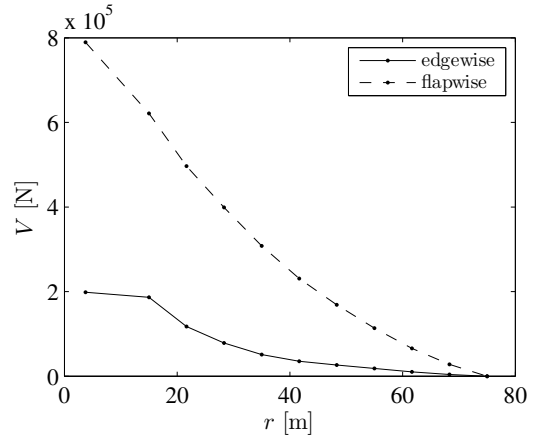

(b)

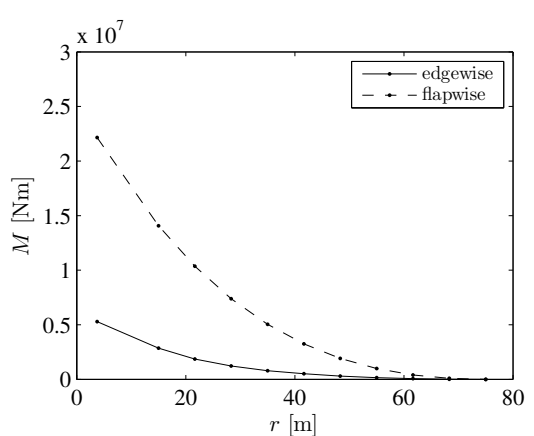

(c)

Fig. 6 Aerodynamic loads for load case 4 (EWM with the horizontal blade at a pitch angle of $\left.57^{\circ}\right)$. (a) Applied load $\left(F^{\prime}\right)$. (b) Shear force $(V)$. (c) Bending moment $(M)$.

\section{Step 1: Topology optimization of a short blade section}

6.1 Finite element model and optimization problem formulation

When selecting the blade section to be modeled, the closest inboard blade section not situated in the blended root section (too large variations of cross section exist in that region) was considered. When referring to the blade geometry described in section 3 , this corresponds to the section situated between chord stations $r=15 \mathrm{~m}$ and $r=21.67 \mathrm{~m}$. To further simplify the model, the local blade section twist and taper were neglected. So, the airfoil chord length and thickness of this modeled blade section are respectively $5.625 \mathrm{~m}$ and $1.69 \mathrm{~m}$.

After testing different methods to model the blade section, a simplified cantilever beam model was favored to run the topology optimization. To accurately recreate blade loading in the section according to the different load cases developed in section 4, a rigid body element (RBE) fixed at the outboard end of the section was used. As shown in figure 7, the use of a RBE gave the possibility to recreate the loading generated by the blade's outboard forces by applying an equivalent resultant shear force and bending moment at the far end of the blade section. For clarity, only flapwise loads are presented on figure 7 but edgewise loads are modeled in a similar fashion. Although the bending moments and shear forces can be reproduced precisely with this technique according to the diagrams presented in section 4, small load differences may exist within the blade section since it was decided to use simplified constant load distributions over the blade section both in the flapwise and edgewise directions instead of the exact non-linear aerodynamic pressure and weight distributions. Since these differences are small and also because the contribution of the distributed loads over the blade's surface is relatively small when compared to the contribution of the shear force and the bending moment at the far end of the blade section, it is believed that

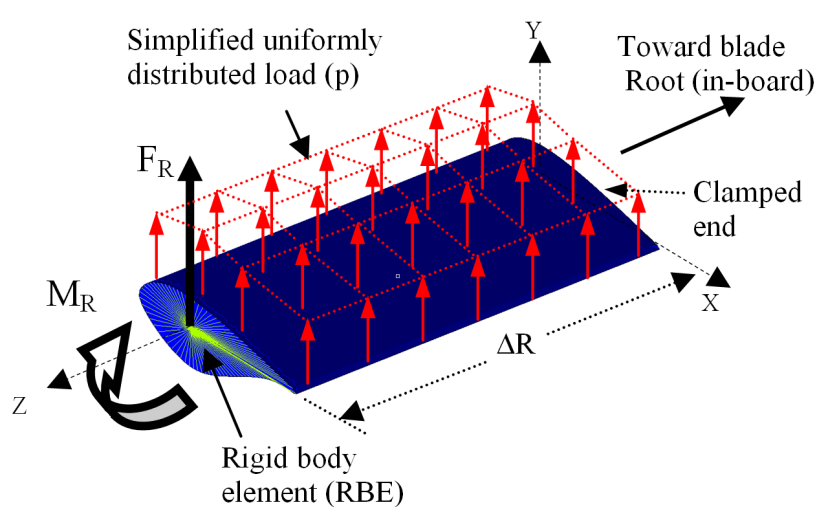

Fig. 7 FE model of the blade section (step 1).

this simplification will not significantly influence the topology optimization results.

From section 4, four critical load cases were retained for design. Being relatively different in nature (bending moment and shear force distribution along blade length), it was suggested that these four load cases should be studied simultaneously to yield a blade design capable of withstanding all load cases. Nevertheless, when studying a short blade section, the load cases can be analyzed to target the single most critical one. When doing so, applying gravity loads and expressing all load cases with respect to a flapwise and edgewise reference system, it was found that the worst loading conditions for the blade section chosen for this study are due to load case 2 for the edgewise direction and the load case 3 for the flapwise direction.

Using the values shown in figure 4 and 5, the equivalent resultant shear forces, bending moments and pressure distributions to be applied on the RBE and the airfoil surface to reproduce loading in the $6.66 \mathrm{~m}$ long blade section were derived. It is worth noting that in the FE model the edgewise uniformly distributed loads will be reproduced by tailoring the element density of non-design elements to match the loading and that the weight of the elements part of the 
design domain will be set to zero for them not to influence loading during the optimization process.

The design variables for the optimization problem are the densities of each solid elements. These densities $\left(\rho_{e}\right.$, should not be confused with the material density) vary from 0 to 1 to modify the elements' stiffness as follow :

$\tilde{\mathbf{K}}_{e}=\rho_{e}^{p} \mathbf{K}_{e}$

where $\mathbf{K}_{e}$ and $\tilde{\mathbf{K}}_{e}$ are respectively the baseline and modified stiffness matrix of the element and $p$ is a penalty factor that helps avoid intermediate values of $\rho_{e}$ (forces values to 0 or 1). Thus, when an element density is 0 , the stiffness of this element is nil (absence of material). When the density is 1 , the baseline material properties are applied to the element. As the optimization process progresses, the density of elements that are not useful to the objective function or to respect the constraints will decrease and the density of useful elements will increase so that the distribution of densities at the end of the computation shows where material is most needed and where it is not. This approach for topology optimization is called density method or Solid Isotropic Material with Penalization (SIMP). More details on this method can be found in Bendsøe and Sigmund (2003) and details on the implementation of SIMP method in Altair's OptiStruct solver can be found in Zhou et al (2004), Thomas et al (2002) and in the OptiStruct documentation (Altair Engineering, inc., 1999).

As discussed earlier, since wind turbine blades need to keep their exterior shape intact for aerodynamic purposes, the FE model had to be described in a way of being able to keep the exterior surface of the blade section intact while allowing the interior volume to be used as the design domain. This was accomplished by using shell elements on the exterior of the blade section and filling the interior volume of these shells with tetrahedral elements. In the OptiStruct environment, the shell elements were labeled as part of a non-design domain whereas the tetrahedral elements were labeled as being part of the design domain. 40,081 4node tetrahedral elements were used in the design domain whereas 9,112 3-node shell shell elements composed the non-design domain. The model contains 9076 nodes. Different material labels were used for the two different domains and a very low stiffness and thickness was given to the shell elements to minimize their contribution to the structure's compliance. Material density was also set to match an approximated blade section weight.

To perform the optimization, two types of response were used: the compliance of the structure and the volume fraction of the design domain. The objective of the optimization problem is to minimize the sum of the compliance of load cases 2 and 3 (defined in section 4.3) with a constraint of 0.2 on the volume fraction of material contained in the design domain. $20 \%$ of the blade volume is then forced to be kept to maximise the structure's stiffness for these load cases. The problem can be expressed as :

$$
\begin{aligned}
& \min _{\rho_{e}} \sum c_{j}, j=1, \ldots, n_{j} \\
& \text { s.t.: } \frac{V\left(\rho_{e}\right)}{V_{0}}=20 \% \\
& 0.0 \leq \rho_{e} \leq 1.0, e=1, \ldots, n_{e}
\end{aligned}
$$

Where $c_{j}$ is the compliance of load case $j, n_{j}$ is the number of load cases (2), $V_{0}$ is the volume of the design domain, $V\left(\rho_{e}\right)$ is the volume of the design domain occupied by material and $n_{e}$ is the number of elements in the design domain. The compliance for a load case is computed as the compliance of the full structure (solid design elements and shell elements). In a finite element model, the compliance is computed as :

$c_{j}=\frac{1}{2} \mathbf{f}^{T} \mathbf{u}$

where $\mathbf{f}$ is the load vector and $\mathbf{u}$ is the nodal displacement vector of the finite element problem (Altair Engineering, inc., 1999). Note that other authors define the compliance as twice the value of the strain energy $\left(c_{j}=\mathbf{f}^{T} \mathbf{u}\right.$; de Ruiter, 2005).

As discussed earlier, to keep the design as simple as possible for cost and manufacturing reasons, an extra constraint should be included in the topology environment to force repetitive patterns along blade length. To try and take this into account, the symmetry function of OptiStruct was used and a symmetry plane perpendicular to the blade section $z$ axis was described at mid span of the model.

\subsection{Results}

The optimal structural layout found when simultaneous applying both load cases is presented in figure 8 where high density regions show places where material is needed and low density regions show places where material is less necessary. These results show that this optimum solution resembles a rib/spar configuration with a large amount of material concentrated in the spar region. It is clear that the solution is designed mainly to hold flapwise loads due to its heavily reinforced upper and lower surfaces. This is understandable since the flapwise bending loads are significantly larger than the edgewise bending loads. The solution also correlates well with the fact that the area moment of inertia in the flapwise direction of the blade section is much smaller than in the edgewise direction, therefore making the structure much weaker in the flapwise direction. On the other hand, it is more difficult to explain why three distinct small web sections support the shear loads (shown on figure 8c). One hypothesis is that three distinct vertical shear webs are better suited to support combined shear loads simultaneously in the flapwise and edgewise directions than classic planar vertical web oriented in the direction of blade length. 

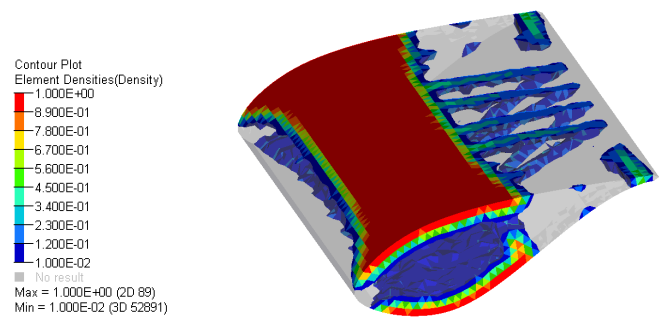

(a)

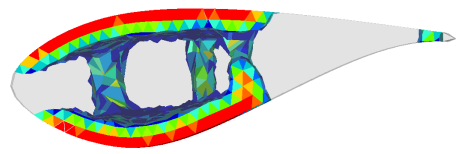

(b)

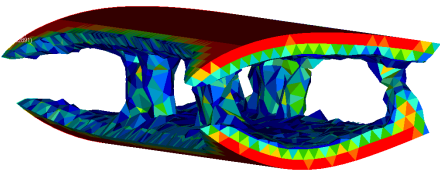

(c)

Fig. 8 Result of the topology optimization (step 1) on the short blade section (density contour plot of design elements), only regions with a density higher than 0.1 are shown.

Although the results presented in figure 8 gave interesting results, some parameters and intrinsic characteristics of the FE model used were identified as being able to significantly influence the topology optimization solutions.

First of all, the boundary conditions set on the blade section to be optimized inevitably created highly stressed areas that can act as starting points to generate discrete structural layouts during the topology optimization process. These boundary conditions have an adverse effect on topology optimization solutions since that by nature, wind turbine blade loading is never concentrated on one point except at the root attachment. Also, when modeling just a short blade section, the optimized structural layout found should normally be considered optimum for that specific blade section only. Since blade loading and design domains are relatively similar from one blade section to another along blade length, it is expected that the solutions shown in figure 8 could also be considered optimum for other airfoils shaped blade sections. On the other hand, this is most certainly not true for blade sections near the root where the design domain changes from an airfoil shape to a circular section.

Of course the best way to confirm or prove wrong the hypotheses just mentioned would be to model the full blade with aerodynamic, inertial and gravity loads, but unfortunately, the big drawback of this approach is the extremely long computational time required to process a much larger model. To make this approach feasible and keep computational time within acceptable limits, a half-blade model was used. The topology optimization result obtained with this model will be presented in the next section.

\section{Step 2: Topology optimization of a half-blade model}

7.1 Finite element model and optimization problem formulation

The finite element model used for the topology optimization of step 2 is shown on figure 9 . To lighten the model, only the section from the root to the $35 \mathrm{~m}$ radial position $(47 \%$ of blade length) was modeled. The upper and lower surfaces and both ends of the blade are meshed with 3-node triangular shell elements. The closed volume formed by these shell elements is filled with 4-node tetrahedral solid elements. These solid elements form the design domain for the topology optimization problem. The model contains 76,456 3-node shell elements, 482,215 4-node tetrahedral elements and 100,058 nodes.

The blade is clamped at its root contour and a rigid body element is created at the $35 \mathrm{~m}$ radial position to apply the equivalent loads normally applied on the outboard blade sections as it was done for the short blade section model. All nodes at that station are connected to a master node (with all degrees of freedom constrained) on which equivalent shear forces, bending moments and normal forces are applied to simulate the aerodynamic, gravitational and inertial loads of the outboard section of the blade. Aerodynamic loads are applied in the finite element model using a MATLAB program instead of being constantly applied lengthwise as it was the case with the previous model. This program extracts the aerodynamic loads to be applied from the BEM code earlier discussed and then reads the connectivity tables (position of nodes and connectivity of elements) of the finite element model to apply the proper pressure on each shell element of the upper and lower surfaces of the blade. For a given radial position, the pressure applied is constant over the chord length.

Again, the properties of the shell elements have been given a very low stiffness $\left(E=1 \times 10^{-6} \mathrm{GPa}\right)$ and thickness $(1 \mathrm{~mm})$. This is done so the shells do not contribute to the structure stiffness and are just used to apply the aerodynamic loads. The design domain (solid elements) uses isotropic material with a Young's modulus of $30 \mathrm{GPa}$ and a Poisson's ratio of 0.3 . Concerning material density, shell elements have no mass whereas the density of material for solid element is adjusted to get a total mass of the blade of $35,000 \mathrm{~kg}$ (in accordance with today's blade mass evolution trend, see for e.g. van Rijswijk et al, 2005). This enables gravitational and centrifugal force to be modeled directly as volume loads in the FE model.

The objective of the optimization problem is to minimize the sum of the compliance of all load cases (defined in sec- 


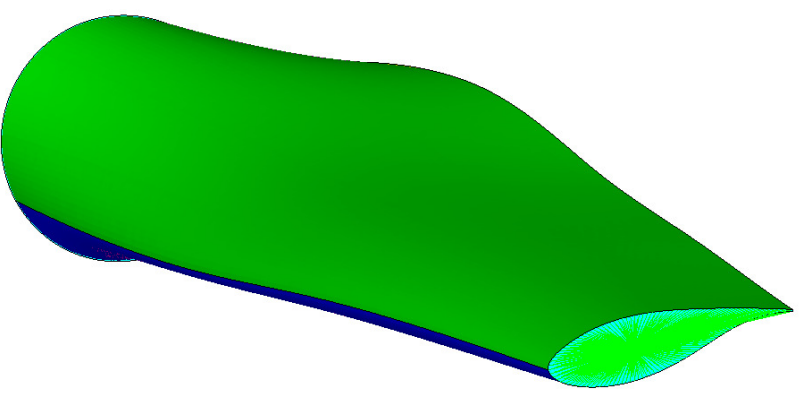

(a)

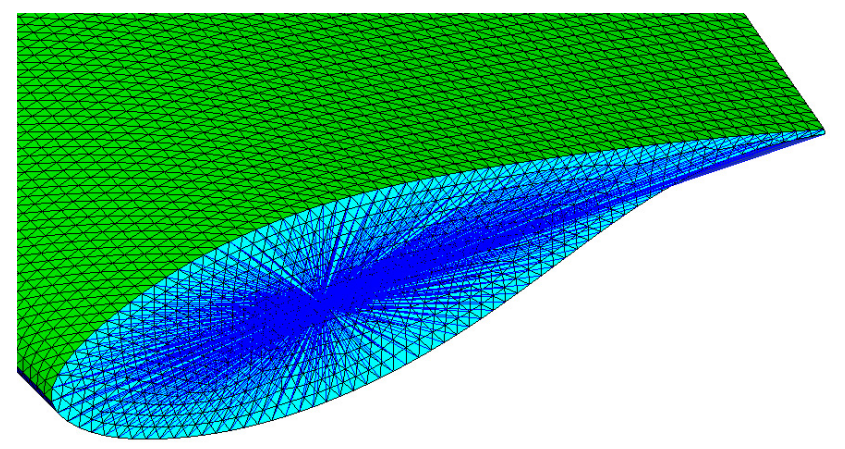

(b)

Fig. 9 Finite element model of the blade for topology optimization (step 2). (a) Blade without mesh. (b) Zoom at the $35 \mathrm{~m}$ radial position (where the blade is cut-off).

tion 4.3) with a constraint of 0.2 on the volume fraction of material contained in the design domain. $20 \%$ of the blade volume is then forced to be kept to maximise the structure's stiffness for all load cases. The problem can be expressed by equation 2 where the number of loadcase $\left(n_{j}\right)$ is 4 .

\subsection{Results}

The results of this optimization problem are shown in figure 10 as a contour plot of the elements' density at the last iteration. As it was the case for step 1, it can clearly be seen on figure 10a that a structure with 2 heavily reinforced spar caps emerges to support the load that his predominantly in the out-of-plane direction. These spar caps are situated in the thickest part of each cross section to maximize sectional inertia.

The location of shear webs is a bit harder to interpret. As it can be seen on figure $10 \mathrm{~b}$, in some sections, a single web is situated at approximately $1 / 3$ of the chord length (typical for small and medium size blades) while for other sections, there is no web. However, a clear closed spar structure (typical for large wind turbine blades) can not be identified.

We can also see on figures $10 \mathrm{a}$ and $10 \mathrm{~b}$ that at the root of the blade, each spar cap splits in two sections. The blade is then attached to the root by four members symmetrically arranged (see figure 11). This topology offers a higher edgewise section modulus than if the two spar caps simply continued until they reached the root. This root attachment configuration gives approximately the same section modulus in the edgewise direction than in the flapwise direction.

An other interesting structural element that can be observed in figure 10 is the presence of ribs in the trailing edge section. These ribs are separated by a distance of 1 to $2 \mathrm{~m}$. The density of these ribs vary from about 0.1 to 0.3 . Even if the density of these members is very low, they appear in a region of near zero density which justifies their presence to support the pressure loads applied in the trailing edge region and reduce the distortion of aerodynamic profiles. These re-

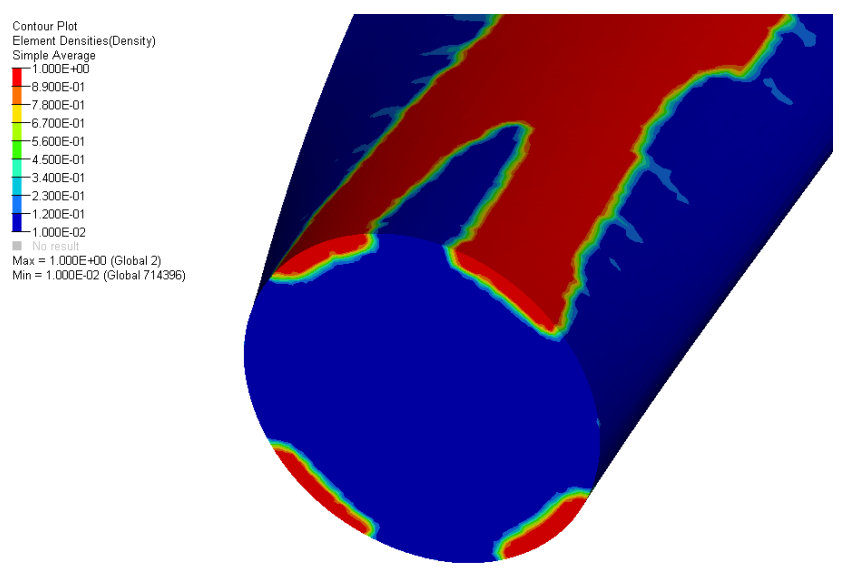

Fig. 11 Result of the topology optimization (density contour plot of design elements) in the root region (step 2).

sults are consistent with results obtained in step 1. Except in the root region, we did not identify new structural members due to the blade twist or taper that had not already been identified in the first step of the optimization process. The spacing between each ribs is also similar in both models (short section and half-blade).

In general, the spar structure seen on figure 10 is a classic structure for wind turbine blades. However, ribs are not seen in today's large size wind turbine blades but should be well adapted for fast melt thermoplastic composite processing. Based on these results, the third step of the optimization process concentrates on refining the design using size optimization on shell elements to study the usefulness of these structural members. The shear web configuration will also be studied. 


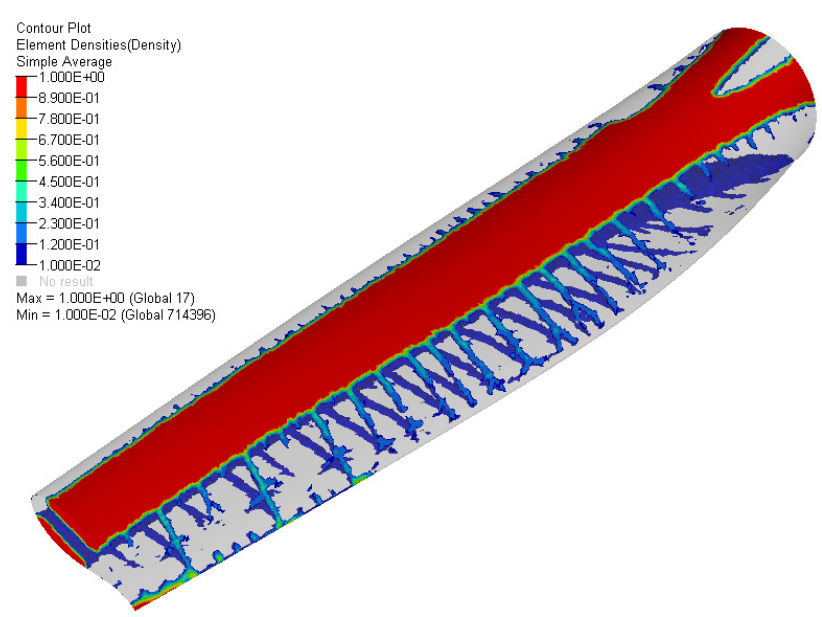

(a)

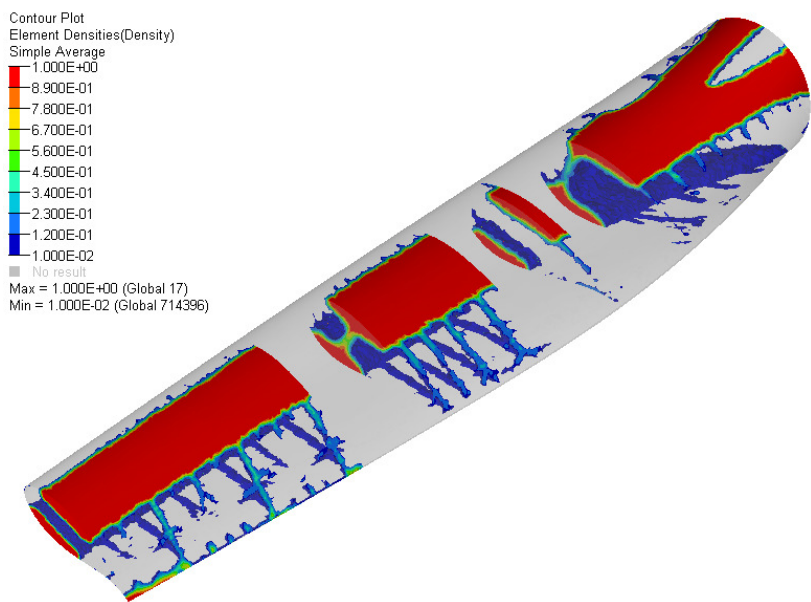

(b)

Fig. 10 Result of the topology optimization (step 2) on the half-blade model (density contour plot of design elements), only regions with a density higher than 0.1 are shown. (a) Full model. (b) Full model with sectional cuts to show the presence of webs.

\section{Step 3: Sizing optimization on shell model}

8.1 Finite element model and optimization problem formulation

As the number and the location of the shear webs are not clear from the results just shown, it was chosen to build a model with 3 webs situated at 15, 33 and $50 \%$ of the chord length (see figure 12b). It is then possible to remove the central web of the finite element model to analyse a model with two shear webs or to remove the forward and aft webs to analyse a model with only one shear web. Ribs were placed at intervals of $1 \mathrm{~m}$. Again, it is also possible to remove some ribs from the finite element model to compare different possibilities of rib number and spacing.

The geometry is split into several areas (115 in total) for which a different composite laminate was defined (different colors in figure 12). The optimization problem is formulated as composite sizing optimization. For every areas, a composite laminate made of 2 layers (a $0^{\circ}$ lengthwise unidirectional layer and a $\pm 45^{\circ}$ biaxial layer) of polyamide- 6 (PA6)/glass fibers (a thermoplastic composite) and 1 layer of foam core is defined. For ribs (where $0^{\circ}$ is in the chordwise direction), a $90^{\circ}$ unidirectional layer is added to the laminate. The properties of these materials are presented in table 4 . As core material rigidity and strength are not included in the finite element formulation, only density is needed. In fact, with the option used to model the laminates in OptiStruct (SMCORE), the core material stiffness is not considered when computing the element stiffness and stresses are not computed in the core. Nevertheless, the presence of core adds bending stiffness to the laminate (increasing buckling strength) by increasing the distance between the neutral axis and the other composite laminas. However, the density of the core is included in the computation of the element mass.
To compare results with classic blade designs, topologies without ribs have been also modeled with epoxy-based composites for which properties are also presented in table 4. In the finite element model, the strength values have been divided by a safety factor of 1.82 , the most severe material safety factor according to the IEC 61400-1 standard.

The design variables in this optimization problem are the thicknesses of each layer of each area. These thicknesses can vary from a near zero value $\left(1 \times 10^{-6} \mathrm{~m}\right)$ to a value of $0.100 \mathrm{~m}$. The option used for computation of the composite laminate properties in the OptiStruct finite element code (SMCORE) was set to homogenize the properties of the composite layers (except for the core which is always in the middle) which makes the laminate properties independent of the stacking sequence. This way, it is possible to define only two or three composite layers to determine the thickness needed for each. The computation of ply stresses (and failure indexes) with this option is valid only when there is no bending in the composite shells. Since the blade is a hollow structure, we suppose that shells are solicited mostly by in-plane loads. The shell thicknesses obtained with this method can then be easily interpreted as a number of plies if the thickness of each individual ply is known.

To determine shell thicknesses, the objective function is set to minimize the mass of the structure while being subjected to these constraints :

- The Composite failure index must stay below 1.0 in every elements;

- The blade tip deflection must stay below 10 m (13\% of its length);

- The Buckling factor must be at least 1.0 (no buckling allowed). 


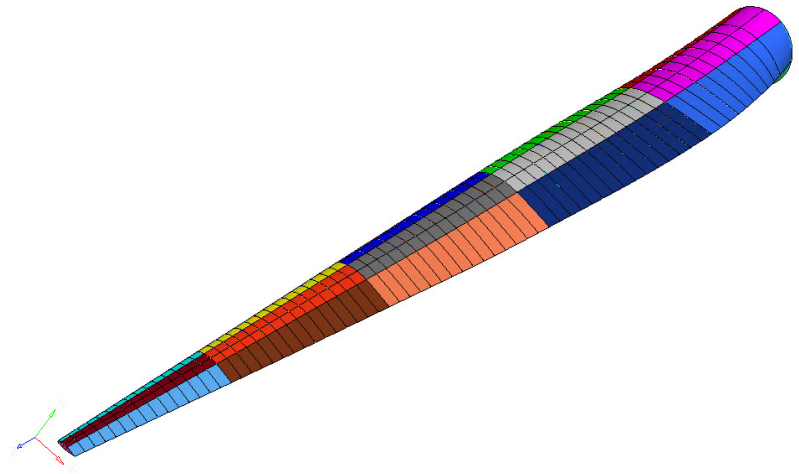

(a)

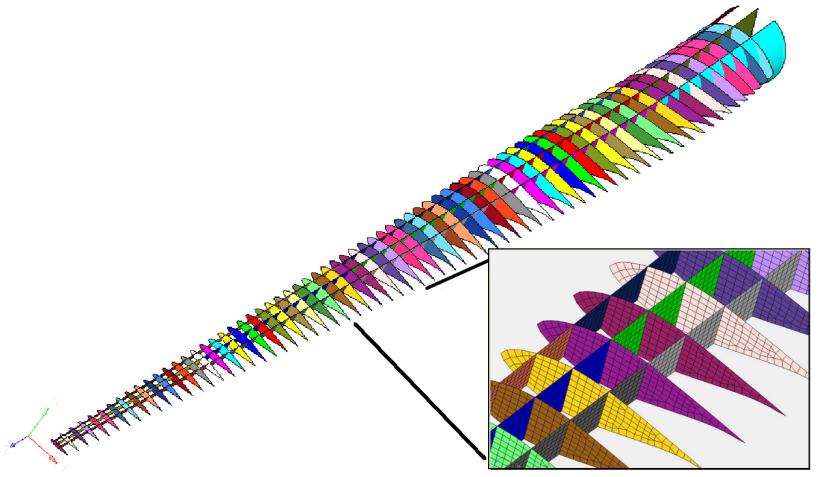

(b)

Fig. 12 Shell finite element model of the blade (step 3). (a) Exterior shape. (b) Interior shape and zoom showing mesh.

Table 4 Properties of materials for the sizing optimization.

\begin{tabular}{|c|c|c|c|c|c|c|c|}
\hline & & & & ass & & lass & Core $^{a}$ \\
\hline & & & $\mathrm{UD}^{b}$ & biaxial $^{c}$ & $\mathrm{UD}^{d}$ & biaxial $^{e}$ & \\
\hline Density & $\rho$ & {$\left[\mathrm{kg} / \mathrm{m}^{3}\right]$} & 1770 & 1800 & 1880 & 1820 & 100 \\
\hline Longitudinal modulus of elasticity & $E_{1}$ & {$[\mathrm{GPa}]$} & 38.0 & 26.0 & 39.2 & 25.2 & \\
\hline Transverse modulus of elasticity & $E_{2}$ & [GPa] & 8.24 & 26.0 & 14.5 & 25.2 & \\
\hline Shear modulus & $G_{12}$ & [GPa] & 1.80 & 4.10 & 4.83 & 3.48 & \\
\hline Tensile longitudinal strength & $S_{1}^{T}$ & {$[\mathrm{MPa}]$} & 869 & 495 & 830 & 476 & \\
\hline Tensile transverse strength & $S_{2}^{T}$ & {$[\mathrm{MPa}]$} & 32.0 & 495 & 53.9 & 476 & \\
\hline Compressive longitudinal strength & $S_{1}^{C}$ & {$[\mathrm{MPa}]$} & 634 & 473 & 523 & 392 & \\
\hline Compressive transverse strength & $S_{2}^{C}$ & {$[\mathrm{MPa}]$} & 72.9 & 473 & 165 & 392 & \\
\hline In-plane shear strength & $S_{12}$ & {$[\mathrm{MPa}]$} & 65.5 & 127 & 78.1 & 93.5 & \\
\hline
\end{tabular}

${ }^{a}$ From Berggreen et al (2007).

${ }^{b}$ From van Rijswijk et al (2005).

${ }^{c}$ From Joncas et al (2006).

${ }^{d}$ From Nijssen (2006).

$e$ From Joncas et al (2006).

This optimization problem can be formulated as :

$$
\begin{array}{ll}
\min _{\mathbf{x}} m & \\
\text { s.t.: } & \delta_{j} \leq 10.0 \mathrm{~m}, j=1, \ldots, n_{j} \\
& \lambda_{j k} \geq 1.0, j=1, \ldots, n_{j}, k=1, \ldots, n_{k} \\
& F_{j e} \leq 1.0, j=1, \ldots, n_{j}, e=1, \ldots, n_{e} \\
0.0 \mathrm{~mm} & \leq x_{i} \leq 100.0 \mathrm{~mm}, i=1, \ldots, n
\end{array}
$$

where $m$ is the blade mass, $\delta_{j}$ is the deflection of the blade tip under load case $j, \lambda_{j k}$ is the buckling index of the $k^{\text {th }}$ mode under load case $j$ and $F_{j e}$ is the Tsai-Wu failure criterion of element $e$ under load case $j . n_{j}$ is the number of load case (4), $n_{k}$ is the number of modes extracted for each load case (5), $n_{e}$ is the number of finite elements in the model and $n$ is the number of design variables $\left(\mathbf{x}=x_{1}, \ldots, x_{n}\right)$. Table 5 shows the number of nodes, elements and design variables for each model investigated.

The initial values of each design variable used as a first guess are presented in table 6 . These values have been estimated for a blade with 2 webs and no ribs using the methodology presented in van Rijswijk et al (2005). To complete the dataset, the initial thickness of the core was set to $10 \mathrm{~mm}$
Table 5 Number of nodes, elements and design variables for each blade model studied in the sizing optimization step.

\begin{tabular}{lccc}
\hline \hline \multicolumn{1}{c}{ Models } & Nodes & Elements & Design variables \\
\hline 2 webs, 0 rib & 48,196 & 49,486 & 124 \\
2 webs, 35 ribs & 52,308 & 55,227 & 260 \\
2 webs, 70 ribs & 56,463 & 61,070 & 400 \\
1 web, 0 rib & 43,409 & 44,028 & 109 \\
1 web, 35 ribs & 47,769 & 49,769 & 245 \\
1 web, 70 ribs & 52,185 & 55,612 & 385 \\
\hline \hline
\end{tabular}

except for ribs where the initial value was set to $3 \mathrm{~mm}$. The initial thickness of the composite layers in the ribs were set to $1 \mathrm{~mm}$ each.

\subsection{Results}

Table 7 shows the results of the sizing optimization of all blade models described in table 5 . For both web configurations, the model with 35 ribs gives the lowest blade mass. When comparing blades with ribs against classic designs, it can be noticed that in general, the presence of ribs can result 
Table 6 First guess values (thicknesses in $\mathrm{mm}$ ) of design variables for spar caps, webs, leading edge and trailing edge.

\begin{tabular}{|c|c|c|c|c|c|c|c|c|c|}
\hline \multirow[t]{2}{*}{$\overline{\text { Sections [m] }}$} & \multicolumn{3}{|c|}{ Spar caps } & \multicolumn{3}{|c|}{ Webs } & \multicolumn{3}{|c|}{ Leading and trailing edges } \\
\hline & UD & biaxial & Total & UD & biaxial & Total & UD & biaxial & Total \\
\hline $3.75-15$ & 64.68 & 27.72 & 92.40 & 5.30 & 5.30 & 10.60 & 8.35 & 8.35 & 16.70 \\
\hline $15-30$ & 38.92 & 16.68 & 55.60 & 5.30 & 5.30 & 10.60 & 8.35 & 8.35 & 16.70 \\
\hline $30-45$ & 31.08 & 13.32 & 44.40 & 4.20 & 4.20 & 8.40 & 6.65 & 6.65 & 13.30 \\
\hline $45-60$ & 22.96 & 9.84 & 32.80 & 3.10 & 3.10 & 6.20 & 4.90 & 4.90 & 9.80 \\
\hline $60-75$ & 10.43 & 4.47 & 14.90 & 2.65 & 2.65 & 5.30 & 2.65 & 2.65 & 5.30 \\
\hline
\end{tabular}

in a slight mass reduction. Furthermore, a blade with around 35 ribs seems to be the optimal topology.

For all models, all three optimization constraint types are active. Analysis of failure index distribution over the blades showed that the failure index in the spar caps are in general much lower than the limit and also lower than in the leading edge, the trailing edge and the webs. It was also observed that the critical region for buckling is the upper trailing edge skin, where the buckling constraints are active for load case 3 . For some blade models, buckling is also a critical constraint in the webs or in the ribs near the root for load case 4. A couple of elements in the leading edge, in the trailing edges and in the web reached the limit value of failure index. Based on these observations, it can be concluded that the thicknesses of spar caps are mainly driven by the rigidity constraints and that the thicknesses of webs, ribs, leading edge and trailing edge are driven by the buckling and/or the composite strength constraints.

Table 8 shows the composite layer thicknesses, fraction of $0^{\circ}$ UD fibers and core thicknesses for the section of the blade extending from 30 to $45 \mathrm{~m}$. As the trends observed in this section are almost the same for the other sections, we will focus on this section to compare the different blade models.

\subsubsection{Spar caps}

As it could have been predicted, spar caps are thicker than other parts of the blade because they support most of the load. In general, the thickness of spar caps are almost the same for all blade models except for the epoxy blades where the thicknesses are a little less because the rigidity of the epoxy/glass UD composite is slightly superior than the PA6/glass UD composite.

The fraction of unidirectional fibers in the spar caps varies from 96 to $98 \%$ to support the load that is predominantly in the axial direction of the blade. This value of UD fraction is high when compared to what can be found in the litterature (70\%, Griffin and Zuteck, 2001; Berggreen et al, 2007), but this can be explained by the fact that the present optimization method does not consider torsional dynamic effects that could increase the need for $\pm 45^{\circ}$ fibers.

\subsubsection{Leading edge and trailing edge skins}

For models with 2 shear webs, the presence of ribs allows the skins to be thinner. When looking at table 8 , it can be concluded that the mass saved because of the reduction of skin and web thickness is directly transferred to the ribs since the spar cap thicknesses remained unchanged. If we compare the PA-6 composite blades with the epoxy-composite blades, we can also observe that the skin thickness of epoxycomposite blades is smaller or in the same range as skin thickness of PA-6 composite blades using ribs. This again can be explained by the fact that the epoxy/glass UD composite properties are slightly better than its PA-6 counterpart.

Lastly, the optimization processes yielded a fraction of UD fibers in the aerodynamic skins that ranges from 50 to $75 \%$. This is a little bit higher than what can be found in the literature. For exemple, Griffin and Zuteck (2001) use about $40 \%$ of UD in the skins in their baseline structural model.

\subsubsection{Webs}

In general, the composite layer thicknesses of the webs (varying from 2.9 to $4.6 \mathrm{~mm}$ ) do not seem to be affected by the number of ribs used in the blade structure. On the other hand, a clear increase in thickness between the two webs concept and the one web concept is noticeable. For both concepts, UD fraction goes from 47 to $71 \%$ and has a tendency to increase with the number of ribs. Since the webs are submitted to important shear loads this large proportion of $\pm 45^{\circ}$ seems logical and is in fact in line with what can be found in the litterature (50\%, Griffin and Zuteck, 2001).

\subsubsection{Ribs}

Since the results showed that the $1 / 3$ ratio between composite layers used at the first iteration remained relatively stable during the optimization process $( \pm 5 \%)$, only the composite total thickness is shown in figure 13. The first thing noticeable on figure 13 is that, for most of the blade, rib thicknesses are smaller than the initial values. Because these parts are small compared to the skins and the spar caps, their influence on the objective function is not very significant. Thus, 
Table 7 Results of sizing optimization: Optimized blade mass with associate active constraints

\begin{tabular}{l|l|ll}
\hline \hline \multicolumn{1}{c|}{ Model } & Optimized mass [kg] & & Active Constraints (load case) \\
\hline 2 webs, 0 rib, PA-6/glass & 30,272 & deflection (3) & buckling (3) failure of 5 elem. (3) \\
2 webs, 35 ribs, PA-6/glass & 29,861 & deflection (3) & buckling (3, 4) \\
2 webs, 70 ribs, PA-6/glass & 29,922 & deflection (3) & buckling (3) failure of 3 elem. (1, 3, 4) \\
1 web, 0 rib, PA-6/glass & 30,342 & deflection (3) & buckling (3, 4) \\
1 web, 35 ribs, PA-6/glass & 29,815 & deflection (3) & buckling (3) failure of 2 elem. (3) \\
1 web, 70 ribs, PA-6/glass & 31,241 & deflection (3, 4) & buckling (3) failure of 11 elem. (1, 3, 4) \\
2 webs, 0 rib, epoxy/glass & 30,070 & deflection (3) & buckling (3, 4) failure of 1 elem. (3) \\
1 web, 0 rib, epoxy/glass & 30,756 & deflection (3) & buckling (3) \\
\hline \hline
\end{tabular}

Table 8 Thickness of composite layers, UD fraction in composite layers and core thickness for the blade region extending from $30 \mathrm{~m}$ to $45 \mathrm{~m}$.

\begin{tabular}{|c|c|c|c|c|c|c|c|c|c|}
\hline & \multirow{3}{*}{$\begin{array}{l}\text { Initial } \\
\text { values }\end{array}$} & \multicolumn{6}{|c|}{ PA-6/Glass } & \multicolumn{2}{|c|}{ Epoxy/Glass } \\
\hline & & 2 webs & 2 webs & 2 webs & 1 web & 1 web & 1 web & 2 webs & 1 web \\
\hline & & $0 \mathrm{rib}$ & 35 ribs & 70 ribs & $0 \mathrm{rib}$ & 35 ribs & 70 ribs & $0 \mathrm{rib}$ & $0 \mathrm{rib}$ \\
\hline \multirow{3}{*}{$\begin{array}{l}\text { Upper surface } \\
\text { leading edge } \\
\text { skin }\end{array}$} & $13.3 \mathrm{~mm}$ & $4.1 \mathrm{~mm}$ & $2.6 \mathrm{~mm}$ & $2.3 \mathrm{~mm}$ & $3.3 \mathrm{~mm}$ & $3.2 \mathrm{~mm}$ & $4.2 \mathrm{~mm}$ & $2.4 \mathrm{~mm}$ & $4.0 \mathrm{~mm}$ \\
\hline & $50 \%$ & $55.6 \%$ & $53.0 \%$ & $55.4 \%$ & $46.6 \%$ & $54.1 \%$ & $53.5 \%$ & $58.7 \%$ & $57.3 \%$ \\
\hline & $10.0 \mathrm{~mm}$ & $8.2 \mathrm{~mm}$ & $7.1 \mathrm{~mm}$ & $7.2 \mathrm{~mm}$ & $9.6 \mathrm{~mm}$ & $7.3 \mathrm{~mm}$ & $8.1 \mathrm{~mm}$ & $6.1 \mathrm{~mm}$ & $7.9 \mathrm{~mm}$ \\
\hline \multirow{3}{*}{$\begin{array}{l}\text { Upper surface } \\
\text { spar cap }\end{array}$} & $44.4 \mathrm{~mm}$ & $88.0 \mathrm{~mm}$ & $88.0 \mathrm{~mm}$ & $87.9 \mathrm{~mm}$ & $87.7 \mathrm{~mm}$ & $85.6 \mathrm{~mm}$ & $89.6 \mathrm{~mm}$ & $83.5 \mathrm{~mm}$ & $82.3 \mathrm{~mm}$ \\
\hline & $70 \%$ & $96.9 \%$ & $97.3 \%$ & $96.9 \%$ & $97.3 \%$ & $97.8 \%$ & $95.6 \%$ & $97.7 \%$ & $97.3 \%$ \\
\hline & $10.0 \mathrm{~mm}$ & $7.6 \mathrm{~mm}$ & $6.6 \mathrm{~mm}$ & $6.8 \mathrm{~mm}$ & $10.3 \mathrm{~mm}$ & $7.1 \mathrm{~mm}$ & $8.1 \mathrm{~mm}$ & $5.6 \mathrm{~mm}$ & $7.4 \mathrm{~mm}$ \\
\hline \multirow{3}{*}{$\begin{array}{l}\text { Upper surface } \\
\text { trailing edge } \\
\text { skin }\end{array}$} & $13.3 \mathrm{~mm}$ & $4.7 \mathrm{~mm}$ & $2.4 \mathrm{~mm}$ & $3.0 \mathrm{~mm}$ & $3.6 \mathrm{~mm}$ & $4.2 \mathrm{~mm}$ & $5.3 \mathrm{~mm}$ & $2.6 \mathrm{~mm}$ & $3.1 \mathrm{~mm}$ \\
\hline & $50 \%$ & $40.6 \%$ & $22.7 \%$ & $16.0 \%$ & $37.3 \%$ & $15.5 \%$ & $26.8 \%$ & $49.6 \%$ & $63.6 \%$ \\
\hline & $10.0 \mathrm{~mm}$ & $20.4 \mathrm{~mm}$ & $19.2 \mathrm{~mm}$ & $15.4 \mathrm{~mm}$ & $24.5 \mathrm{~mm}$ & $14.5 \mathrm{~mm}$ & $12.4 \mathrm{~mm}$ & $23.9 \mathrm{~mm}$ & $25.5 \mathrm{~mm}$ \\
\hline \multirow{3}{*}{$\begin{array}{l}\text { Lower surface } \\
\text { leading edge } \\
\text { skin }\end{array}$} & $13.3 \mathrm{~mm}$ & $5.7 \mathrm{~mm}$ & $4.5 \mathrm{~mm}$ & $5.5 \mathrm{~mm}$ & $3.8 \mathrm{~mm}$ & $5.1 \mathrm{~mm}$ & $10.2 \mathrm{~mm}$ & $3.5 \mathrm{~mm}$ & $4.4 \mathrm{~mm}$ \\
\hline & $50 \%$ & $63.7 \%$ & $62.9 \%$ & $61.7 \%$ & $61.1 \%$ & $65.6 \%$ & $71.8 \%$ & $68.1 \%$ & $59.6 \%$ \\
\hline & $10.0 \mathrm{~mm}$ & $8.2 \mathrm{~mm}$ & $7.1 \mathrm{~mm}$ & $7.3 \mathrm{~mm}$ & $7.0 \mathrm{~mm}$ & $7.4 \mathrm{~mm}$ & $8.1 \mathrm{~mm}$ & $6.1 \mathrm{~mm}$ & $7.7 \mathrm{~mm}$ \\
\hline \multirow{3}{*}{$\begin{array}{l}\text { Lower surface } \\
\text { spar cap }\end{array}$} & $44.4 \mathrm{~mm}$ & $84.8 \mathrm{~mm}$ & $84.5 \mathrm{~mm}$ & $83.9 \mathrm{~mm}$ & $80.3 \mathrm{~mm}$ & $82.8 \mathrm{~mm}$ & $80.4 \mathrm{~mm}$ & $82.9 \mathrm{~mm}$ & $80.7 \mathrm{~mm}$ \\
\hline & $70 \%$ & $96.8 \%$ & $97.3 \%$ & $98.0 \%$ & $98.1 \%$ & $97.6 \%$ & $95.5 \%$ & $97.0 \%$ & $97.3 \%$ \\
\hline & $10.0 \mathrm{~mm}$ & $7.5 \mathrm{~mm}$ & $6.4 \mathrm{~mm}$ & $6.7 \mathrm{~mm}$ & $5.9 \mathrm{~mm}$ & $6.9 \mathrm{~mm}$ & $7.8 \mathrm{~mm}$ & $5.0 \mathrm{~mm}$ & $7.1 \mathrm{~mm}$ \\
\hline \multirow{3}{*}{$\begin{array}{l}\text { Lower surface } \\
\text { trailing edge } \\
\text { skin }\end{array}$} & $13.3 \mathrm{~mm}$ & $2.4 \mathrm{~mm}$ & $1.5 \mathrm{~mm}$ & $0.8 \mathrm{~mm}$ & $2.1 \mathrm{~mm}$ & $1.6 \mathrm{~mm}$ & $1.5 \mathrm{~mm}$ & $2.5 \mathrm{~mm}$ & $2.2 \mathrm{~mm}$ \\
\hline & $50 \%$ & $58.1 \%$ & $60.8 \%$ & $72.2 \%$ & $75.5 \%$ & $76.5 \%$ & $68.2 \%$ & $62.3 \%$ & $61.5 \%$ \\
\hline & $10.0 \mathrm{~mm}$ & $8.0 \mathrm{~mm}$ & $8.3 \mathrm{~mm}$ & $7.5 \mathrm{~mm}$ & $12.6 \mathrm{~mm}$ & $13.3 \mathrm{~mm}$ & $8.9 \mathrm{~mm}$ & $7.6 \mathrm{~mm}$ & $10.6 \mathrm{~mm}$ \\
\hline \multirow{3}{*}{ Center web } & $8.4 \mathrm{~mm}$ & & & & $4.2 \mathrm{~mm}$ & $3.9 \mathrm{~mm}$ & $3.5 \mathrm{~mm}$ & & $4.6 \mathrm{~mm}$ \\
\hline & $50 \%$ & & & & $46.6 \%$ & $66.6 \%$ & $71.1 \%$ & & $57.3 \%$ \\
\hline & $10.0 \mathrm{~mm}$ & & & & $9.0 \mathrm{~mm}$ & $8.9 \mathrm{~mm}$ & $7.8 \mathrm{~mm}$ & & $8.5 \mathrm{~mm}$ \\
\hline \multirow{3}{*}{ Aft web } & $8.4 \mathrm{~mm}$ & $3.1 \mathrm{~mm}$ & $2.9 \mathrm{~mm}$ & $3.3 \mathrm{~mm}$ & & & & $3.4 \mathrm{~mm}$ & \\
\hline & $50 \%$ & $62.9 \%$ & $65.8 \%$ & $68.1 \%$ & & & & $49.6 \%$ & \\
\hline & $10.0 \mathrm{~mm}$ & $8.7 \mathrm{~mm}$ & $8.8 \mathrm{~mm}$ & $7.8 \mathrm{~mm}$ & & & & $7.2 \mathrm{~mm}$ & \\
\hline \multirow{3}{*}{ Forward web } & $8.4 \mathrm{~mm}$ & $3.6 \mathrm{~mm}$ & $2.6 \mathrm{~mm}$ & $3.2 \mathrm{~mm}$ & & & & $2.0 \mathrm{~mm}$ & \\
\hline & $50 \%$ & $55.2 \%$ & $57.4 \%$ & $51.9 \%$ & & & & $54.9 \%$ & \\
\hline & $10.0 \mathrm{~mm}$ & $8.4 \mathrm{~mm}$ & $6.9 \mathrm{~mm}$ & $7.2 \mathrm{~mm}$ & & & & $7.0 \mathrm{~mm}$ & \\
\hline
\end{tabular}

the optimization problem can converge before the rib thicknesses have reached their optimized values. This observation can be related to the fact that a slight reduction in rib thickness is noticeable from the tip to the blade mid-span. Ribs at mid-span are larger than ribs at tip so their influence on the objective function is more important. This translates in a larger reduction of their thickness. However, analysis of models optimized with 35 or 70 ribs shows that the buckling and composite strength constraints can not be respected if ribs are removed. This proves that the rib thicknesses from tip to blade mid-span could not converge to a value of 0 .

At the root region, composite layer thicknesses are higher than the initial values indicating that ribs up to $5 \mathrm{~mm}$ thick are needed to avoid buckling of the ribs and the skins.
Finally, on a global level, one can notice localized rib thickening at the $15 \mathrm{~m}, 30 \mathrm{~m}$ and $45 \mathrm{~m}$ blade stations. As explained earlier, this corresponds to the areas where skin thickness changes from one section to the other (ply drop) forcing ribs to be slightly thicker to compensate local skin instability.

\subsubsection{Core thickness}

The optimized core thickness is almost always lower than its initial value of $10 \mathrm{~mm}$ except in regions where buckling can be a concern. As for the ribs, the core being really light, it does not have an important effect on the objective function (minimizing mass). Therefore, the results obtained for regions not submitted to compressive loads are hard to inter- 


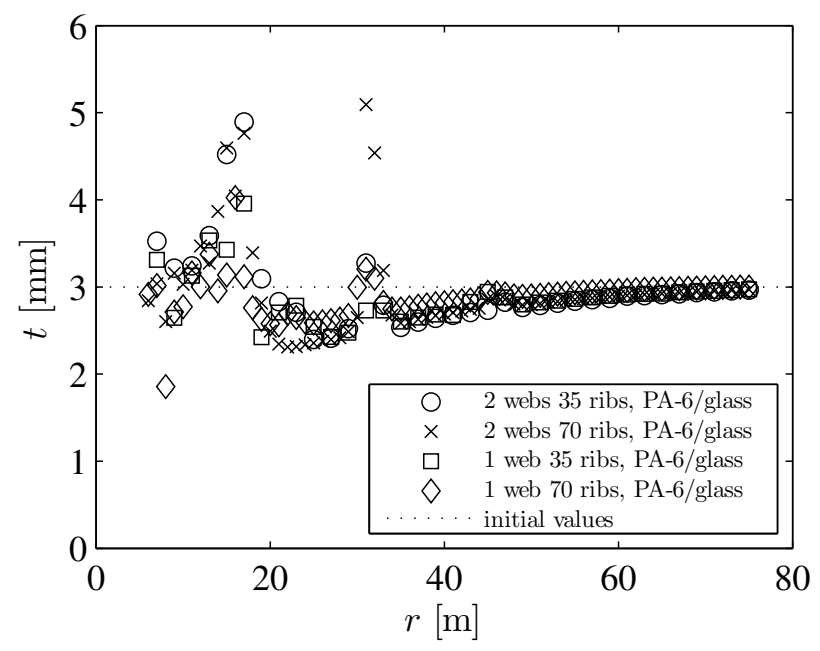

(a)

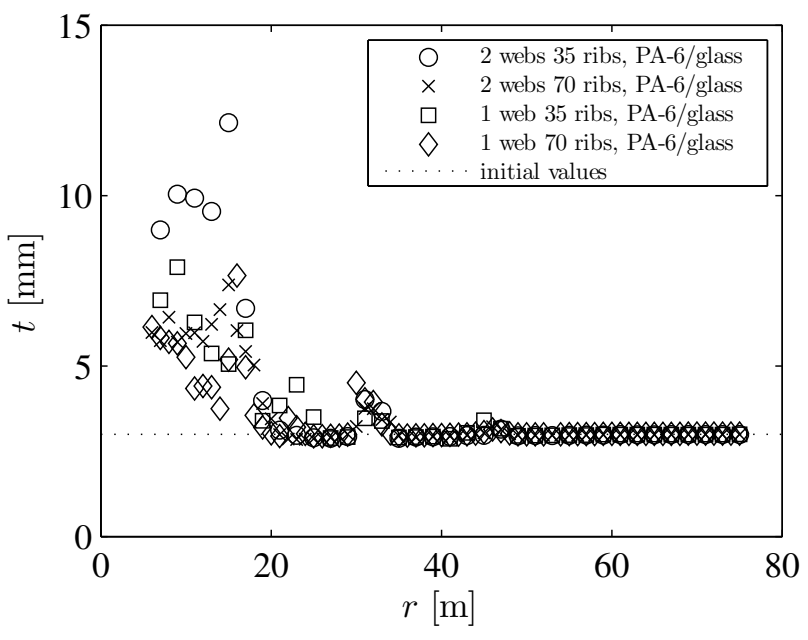

(b)

Fig. 13 Rib thickness $(t)$ along the blade span ( $r$ ) for the different blade models. (a) Composite layers. (b) Core.

pret because core thicknesses may not have reached their optimized values before the optimization problem converged. However, core thicknesses in regions of the blade that are prone to buckle (upper surface trailing edge skins) can be considered more optimum. As seen in table 8, core thickness in these regions varies from 12.4 to $24.5 \mathrm{~mm}$ and values increase as the number of webs and the number of ribs decrease. These results show the usefulness of core material to increase the buckling strength of parts submitted to compressive load. It also shows that the presence of ribs increases buckling strength of the blade skins.

\subsubsection{Thickness variation along the blade span}

Figure 14 shows the variation of composite layer thicknesses for different sections along the blade. In figure 14a, we can see that the maximum thickness of the upper spar cap (it is the same thing for the lower spar car) is situated at blade mid-span. Even if the bending moment is higher towards blade root, the reduction in thickness of the aerodynamic profiles towards blade tip causes the need for thicker laminates to reach values of section modulus that are sufficient to respect the maximum deflection constraints.

In other sections (lower surface leading edge (figure 14b), upper surface leading edge and upper surface trailing edge), the thickness of the composite layers tapers off towards blade tip in a more conventional way. For the other sections like the webs (figure 14c shows the aft webs) and the lower surface trailing edge, thicknesses reduce from the root to the middle of the blade and then increase towards the tip. This could again be explained by the fact that the reduction of thickness of the aerodynamic profiles towards the tip has to be counterbalanced by an increase of composite layer thicknesses.

\section{Conclusion}

The optimization process presented in this study has shown that the use of ribs could be promising for the construction of future large thermoplastic wind turbine blades. The topology optimization steps (1 and 2) have shown that ribs appear to maximize the rigidity of the structure when a given amount of material is forced to be used. The sizing optimization step has shown that the use of ribs helps to reduce the thickness of aerodynamic shells and that a number of ribs around 35 (between 0 and 70) could be the optimum topology when the objective is to reduce the mass. The mass reduction being limited to about $1.5 \%$, it is hard to conclude that the rib concept has a major effect on blade mass reduction.

It was argued in the introduction that to maximize the potential of TPC when used for wind turbine blade structures, it is essential to redesign the structure with respect to existing TPC material and manufacturing strong points.

In this context, as mentioned in section 2, a blade topology with ribs could be well adapted for thermoplastic composite manufacturing processes since ribs can be produced with fast and low cost press forming techniques. A structure with 2 webs, like the one developed in this paper, is also well adapted for TPC because the blade is clearly separated in three different structures: the spar, the leading edge and the trailing edge. Having three distinct sections gives this configuration an advantage over its one web counterpart. Working with a closed-cell main load carrying structural member helps in controlling load paths and minimizes the load transferred to the buckling prone trailing edge section. It also offers the possibility to easily manufacture the box-spar in a different material than the leading edge and trailing edge section. As it was the case in the aeronautic industry, TPC composites could then first be used in wind turbine blade 


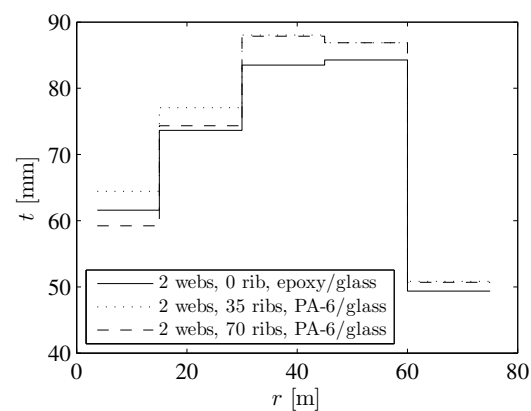

(a)

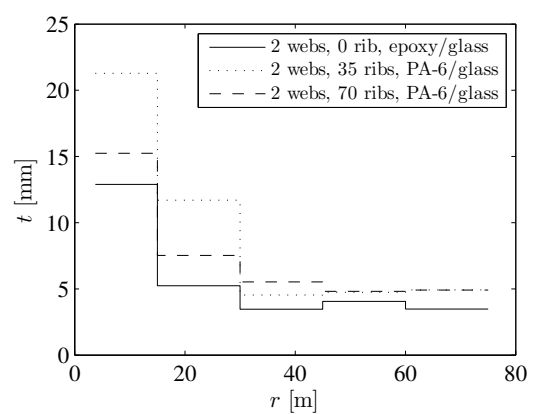

(b)

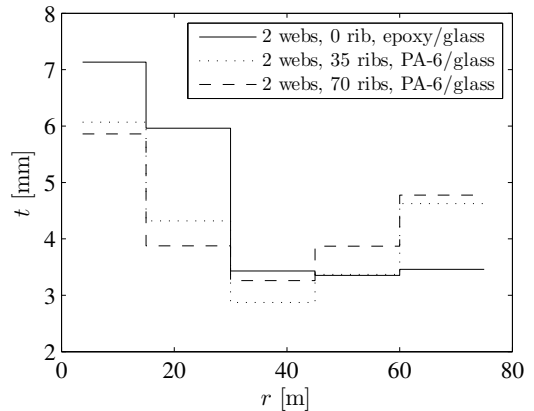

(c)

Fig. 14 Composite layers thicknesses $(t)$ along the blade span (r). (a) Upper surface spar cap. (b) Lower surface leading edge. (c) Aft web.

structures as secondary structure components, i.e. the boxspar still being made with thermoset composites. Gaining manufacturing experience with these non-structural components could help manufacturers minimize the risk when introducing this new material.

As future work, the next step of the design process would be to determine the number of plies of each type based on the layer thickness obtained in the sizing optimization and then, perform a stacking sequence optimization using the same objective and constraints as in the third step of the optimization process. This will lead to a more exact stress computation than with the SMCORE option (that supposes mostly in-plane loads).

Also, as it was shown by Jensen (2008), the failure of a wind turbine blade is highly dependent of non-linear effects due to the distortion of the aerodynamic shape of the section. These effects will have to be studied in the following steps of blade design. Nevertheless, since Jensen also showed that ribs can increase the strength of a blade when submitted to flapwise static loading by up to $30 \%$, the blade structural layout proposed in this paper is expected to limit these undesired cross-section distortions that are known to lead to premature blade failure.

\section{References}

Altair Engineering, inc (1999) Optistruct User Manual. Altair Engineering, inc., Troy (Michigan, United States)

Amorosi S (2004) Application of topology, size and shape optimization on the 787 wing leading edge structure. In: Hyperworks Technology Conference (HTC) 2006, Troy (Michigan, United States), 26-27 September

Bendsøe M, Sigmund O (2003) Topology Optimization : Theory, Methods and Applications. Springer-Verlag, Berlin, Heidelberg (Germany)

Berggreen C, Branner K, Jensen JF, Schultz JP (2007) Application and analysis of sandwich elements in the primary structure of large wind turbine blades. Journal of Sandwich Structures and Materials 9:525-551
Chen CJ, Young C (2004) Integrated topology/shape/size optimzation into upfront automotive component design. In: 10th AIAA/ISSMO Multidisciplinary Analysis and Optimization Conference, Albany (New York, United States), 30 August - 1st September, pp 3252-3259

Griffin DA (2002) Alternative materials, manufacturing process and structural design for large wind turbine blades. In: 2002 ASME Wind Energy Symposium / 40th AIAA Aerospace Sciences Meeting and Exhibit, Reno (Nevada, United States), 14-17 June

Griffin DA, Zuteck MD (2001) Scaling of composite wind turbine blades for rotor of 80 to 120 meter diameter. Journal of Solar Energy Engineering 123:310-318

Hansen MO (2008) Aerodynamics of Wind Turbines, 2nd edn. James \& James, London (United Kingdom)

International Electrotechnical Commission (1999) Wind Turbine Generator Systems - Part 1 : Safety Requirements, 2nd edn. IEC 61400-1, International Electrotechnical Commission, Geneva (Switzerland)

JEC Composites (2009) Global market scenario: Dynamics of the composites industry, 2009 release. JEC Composites

Jensen FM (2008) Ultimate strength of a large wind turbine blade. PhD thesis, Risø National Laboratory for Sustainable Energy, Technical University of Denmark, Roskilde (Denmark)

Joncas S, de Ruiter MJ, van Keulen F (2004) Preliminary design of large wind turbine blades using layout optimization techniques. In: 10th AIAA/ISSMO Multidisciplinary Analysis and Optimization Conference, Albany (New York, United States), 30 August - 1st September

Joncas S, Bergsma O, Beukers A (2005) Power regulation and optimization of offshore wind turbine through trailing edge flap control. In: 43rd AIAA Aerospace Sciences Meeting and Exhibit, Reno (Nevada, United States), 1013 January

Joncas S, van Rijswijk K, Thibault-Liboiron K, Bersee H, Beukers A (2006) Mechanical properties of vacuum infused anionic polyamide-6 (APA-6) glass fiber composites: A benchmark study. In: 27th SAMPE Europe Inter- 
national Conference, Paris (France), 27-29 March

Krog L, Tucker A, Kemp M, Boy R (2004) Topology optimisation of aircraft wingbox ribs. In: 10th AIAA/ISSMO Multidisciplinary Analysis and Optimization Conference, Albany (New York, United States), 30 August - 1st September

Laino DJ, Hansen AC (2002) User's guide to the wind turbine aerodynamics computer software AERODYN. http://wind.nrel.gov/designcodes/ simulators/aerodyn/AeroDyn.pdf

Laino DJ, Hansen AC (2003) User's guide to the wind turbine dynamics computer program YAWDYN. http://wind.nrel.gov/designcodes/ simulators/yawdyn/YawDyn.pdf

Lystrup A (2006) Vacuum consolidation of thermoplastic composites for wind turbine rotor blades. In: Proceedings of the 27th Ris $\varnothing$ international symposium on materials science, Roskilde (Denmark), 4-7 September

Lystrup A, Andersen TL, Knudsen H, Vestergaard T, Lilleheden L, Vestergaard J (1998) Hybrid yarn for thermoplastic fibre composites. Tech. Rep. Ris $\emptyset-\mathrm{R}-1034(\mathrm{EN})$, Risø National Laboratory, Roskilde (Denmark)

Nijssen R (2006) Optidat database reference document. Tech. Rep. 10224 (OB_TC_R018 rev. 005), Optimat Blades, http://www.wmc.eu/optidat_files/ Optidat\%20reference\%20document.pdf, Database: http://www.wmc.eu/optidat_files/Optidat_ _public.zip

van Rijswijk K (2007) Thermoplastic composite wind turbine blades: Vacuum infusion technology for anionic polyamide-6 composites. PhD thesis, Delft University of Technology, Delft (The Netherlands)

van Rijswijk K, Joncas S, Bersee H, Bergsma O, Beukers A (2005) Sustainable vacuum-infused thermoplastic composites for MW-size wind turbine blades - preliminary design and manufacturing issues. Journal of Solar Energy Engineering 127:570-580

de Ruiter MJ (2005) Topology optimization using topology description function approach. $\mathrm{PhD}$ thesis, Delft University of Technology, Delft (The Netherlands)

Thomas H, Zhou M, Schramm U (2002) Issues of commercial optimization software development. Structural and Multidisciplinary Optimization 23:97-110

Timmer W, van Rooij R (2003) Summary of the delft university wind turbine dedicated airfoils. Journal of Solar Energy Engineering 125:488-496

Veers PS, Ashwill TD, Sutherland HJ, Laird DL, Lobitz DW, Griffin DA, Mandell JF, Musial WD, Jackson K, Zuteck M, Miravete A, Tsai SW, Richmond JL (2003) Trends in the design, manufacture and evaluation of wind turbine blades. Wind Energy 6:245-259

Zhou M, Pagaldipti N, Thomas H, Shyy Y (2004) An integrated apporach to topology, sizing and shape opti- mization. Structural and Multidisciplinary Optimization 26:308-317 